\title{
APLICAÇÃO FOLIAR DE POTÁSSIO NA CULTURA DO ARROZ IRRIGADO
}

DARIO, Geraldo José Aparecido ${ }^{1}$

DARIO, Iuri Stéfano Negrisiolo ${ }^{2}$

VAZQUEZ, Gisele Herbst ${ }^{3}$

PERES, Amanda Ribeiro ${ }^{4}$

RESUMO: Na produção de arroz irrigado, o aperfeiçoamento técnico e tecnológico tem propiciado incremento na produtividade de grãos. Nesse sentido, a utilização de fertilizantes foliares, aplicados próximos ao final do ciclo da cultura, poderá proporcionar uma complementação nutricional no momento em que a translocação de fotoassimilados para os grãos é determinante para o rendimento. Diante disso, o presente ensaio teve como objetivo avaliar a interferência da aplicação foliar de potássio em diversos estádios fenológicos da cultura do arroz irrigado sobre o rendimento de grãos e os seus componentes. O experimento foi realizado em três condições de campo no estado do Rio Grande do Sul: nos municípios de Rio Grande utilizando o cultivar IRGA 424, Cidreira com o cultivar Puitá INTA CL e Cachoeira do Sul com o cultivar IRGA 417. O delineamento experimental utilizado nas três localidades foi o de blocos ao acaso, com nove tratamentos e quatro repetições. Os tratamentos receberam aplicações de Ajifol + Amino Plus no início do perfilhamento e posteriormente, de Ajifol K em épocas distintas, ou seja, no início da formação do primórdio floral, no emborrachamento e no início do florescimento. Concluiu-se que a aplicação foliar de potássio na cultura do arroz irrigado não interfere nos componentes de produção de todos os cultivares utilizados e no rendimento de grãos dos cultivares IRGA 424 e IRGA 417. A aplicação foliar de potássio no perfilhamento, início da formação do primórdio floral e no estádio de emborrachamento proporciona maior rendimento da cultivar Puitá INTA CL.

Palavras-chave: Oryza sativa, rendimento, fertilizante foliar, potássio, arroz inundado.

\section{LEAF APPLICATION OF POTASSIUM IN IRRIGATED RICE}

SUMMARY: In the production of irrigated rice, the technical and technological improvement has provided increased productivity. In this sense, the use of foliar fertilizers applied near the end of the cycle may provide a nutritional complementation at the time that the translocation of assimilates to the grains is crucial to yield. Therefore, the objective of this research was to evaluate the interference of foliar application of potassium in different phenological stages of irrigated rice on the components and grain yield. The experiment was performed in three field conditions in Rio Grande do Sul, in the municipality of Rio Grande using the cultivar IRGA 424, in the municipality of Cidreira with cultivar Puita INTA CL and in the municipality of Cachoeira do Sul with the cultivar IRGA 417. The experimental design used in the three locations was a randomized block design with nine treatments and four replications. The treatments received applications of Ajifol + Amino Plus at the beginning of tillering and subsequently, of Ajifol $\mathrm{K}$ at different times, in other words, at the beginning of flowering differentiation stage, at booting and at flowering. It was concluded that foliar application of potassium in the irrigated rice does not interfere in the production components in all cultivars used and in grain yield of the cultivars IRGA 424 and IRGA 417 . The foliar application of potassium in the tillering, beginning of flowering differentiation stage and in the booting stage provides greater yield of the cultivar Puita INTA CL.

Keywords: Oryza sativa, yield, foliar fertilizer, potassium, irrigated rice.

\section{INTRODUÇÃO}

O arroz (Oryza sativa L.) é um dos principais cereais consumidos pela população mundial e sua produção representa cerca de 30\% dos grãos produzidos no mundo (HE et al., 2006; YADAV; JINDAL, 2008; LUANGMALAWAT et al., 2008). O crescimento acelerado da população está aumentando a demanda do

\footnotetext{
${ }^{1}$ Prof $^{\circ}$. Dro ${ }^{\circ}$ ESALQ/USP, Departamento de Produção Vegetal, SP.

2 Acadêmico em Engenharia Agronômica pela ESALQ/USP, SP.

3 Prof $^{a}$. Dr ${ }^{\mathrm{a}}$. UNESP/Ilha Solteira, SP e UNICASTELO/Fernandópolis, SP, endereço: UNICASTELO, caixa postal 121, CEP 15600-000, gisele-agro@uol.com.br

${ }^{4}$ Mestranda em Sistemas de Produção pela UNESP Campus de Ilha Solteira, SP.
} 
produto em proporções não compatíveis com o crescimento da produção, ou seja, a produção mundial de arroz não vem acompanhando o crescimento do consumo (SANTOS; RABELO, 2004).

O Brasil produziu na safra de 2010/2011, de acordo com dados preliminares, 13.613 mil toneladas de arroz, sendo o Rio Grande do Sul o maior estado produtor com 8.904 mil toneladas (CONAB, 2011) responsável por $65,4 \%$ da produção brasileira, com o predomínio do sistema irrigado.

Na produção de arroz irrigado do Rio Grande do Sul, o aperfeiçoamento técnico e tecnológico que vem sendo proposto pelos órgãos de pesquisa e adotado pelos produtores, tem propiciado incremento no rendimento de grãos. Para a manutenção dessa condição ou mesmo superação dos patamares atuais, o manejo correto da nutrição de plantas torna-se indispensável. Nesse sentido, a utilização de fertilizantes foliares, aplicados próximos ao final do ciclo da cultura poderá proporcionar uma complementação nutricional, no momento em que a translocação de fotoassimilados para os grãos é determinante para o rendimento (NTANOS; KOUTROUBAS, 2002). De acordo com Borkert (1987), os fundamentos científicos para esta resposta na cultura da soja baseiam-se no fato de que, do início do estádio reprodutivo até a maturação, ou seja, da floração em diante, a atividade radicular e a absorção diminuem, ao mesmo tempo em que há grande translocação de nutrientes das folhas para as sementes em formação. Assim, a reposição dos nutrientes nas folhas, através de adubação foliar, poderia manter a taxa de fotossíntese por um tempo maior, o que possivelmente refletir-se-ia em maior produção.

A adubação foliar está entre as várias maneiras de fornecer nutrientes às plantas, sendo muitas vezes a alternativa mais eficiente para a solução de problemas específicos e/ou complemento de uma adubação racional. Em culturas extensivas, a adubação foliar com macronutrientes seria um complemento (e não substituto) da adubação feita no solo, principalmente para $\mathrm{N}, \mathrm{P}$ e $\mathrm{K}$, mas podendo ser utilizada também na correção de deficiências eventuais, como cobertura de N e K (FAQUIN, 2005).

Atualmente no mercado, há diversas opções de fertilizantes foliares, como por exemplo, o Ajifol Potássio®, porém pouco se sabe sobre sua eficiência na cultura do arroz. De acordo com Ajinomoto (2011) esse fertilizante foliar é composto por 25,0\% (335 g/L) de $\mathrm{K}_{2} \mathrm{O}$ e 3,0\% (40,2 g/L) de TOC (Carbono Orgânico Total).

Após o nitrogênio, o potássio é o nutriente absorvido em maior quantidade pela maioria das plantas (MARSCHNER, 1995), sendo na cultura do arroz, o nutriente mais absorvido (FORNASIERI FILHO; FORNASIERI, 2006; BARBOSA FILHO, 2001). O potássio é um elemento essencial para todos os organismos vivos, sendo o cátion mais importante nos processos fisiológicos das plantas, não somente pela sua concentração nos tecidos vegetais, mas também pelas suas funções bioquímicas (MENGEL; KIRKBY, 2001). O potássio participa da translocação dos carboidratos sintetizados no processo fotossintético, da síntese proteica e da ativação enzimática, sendo que em casos de deficiência algumas plantas passam a acumular carboidratos solúveis e reduzem o acúmulo de amido e compostos nitrogenados. É absorvido na forma de $\mathrm{K}^{+}$, não sofrendo alterações em sua forma no interior das plantas (MARSCHNER, 1995).

Diante disso, o presente ensaio teve como objetivo avaliar a interferência da aplicação foliar de potássio em diversos estádios fenológicos da cultura do arroz irrigado sobre o rendimento de grãos e os seus componentes.

\section{MATERIAL E MÉTODOS}

O ensaio foi conduzido em três condições de campo no estado do Rio Grande do Sul: Granja Quatro Irmãoslocalizada no município de Rio Grande( $32^{\circ} 17^{\prime} 54^{\prime \prime} \mathrm{LS}$, 52 $42^{\circ} 31^{\prime \prime} \mathrm{LW}$ e altitude $9 \mathrm{~m}$ ), Fazenda Pitangueiras no município de Cidreira (30 $0^{\circ} 11^{\prime} 13^{\prime \prime} \mathrm{LS}, 50^{\circ} 32^{\prime}$ '59' LW e altitude $10 \mathrm{~m}$ ) e Estação Experimental

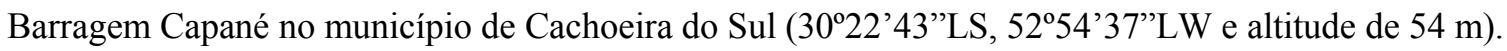


Antes da instalação do experimento foram realizadas análises química e granulométrica dos solos dos três locais do estudo (Tabela 1).

Tabela 1. Análises química e granulométrica dos três solos onde foi instalado o experimento.

\begin{tabular}{|c|c|c|c|c|}
\hline & & $\begin{array}{l}\text { Granja } \\
\text { Quatro } \\
\text { Irmãos }\end{array}$ & $\begin{array}{c}\text { Fazenda } \\
\text { Pitangueiras }\end{array}$ & $\begin{array}{c}\text { Estação } \\
\text { Experimental } \\
\text { Barragem } \\
\text { Capané }\end{array}$ \\
\hline $\mathrm{pH}$ & $\mathrm{CaCl}_{2}$ & 4,9 & 4,1 & 4,0 \\
\hline M.O. & $\mathrm{g} \mathrm{dm}^{-3}$ & 28 & 15 & 18 \\
\hline $\mathrm{P}$ & $\mathrm{mg} \mathrm{dm}^{-3}$ & 10 & 6 & 5 \\
\hline $\mathrm{K}$ & \multirow{7}{*}{ 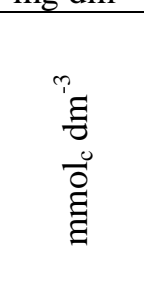 } & 1,7 & 1,3 & 1,6 \\
\hline $\mathrm{Ca}$ & & 39 & 5 & 6 \\
\hline $\mathrm{Mg}$ & & 15 & 1 & 2 \\
\hline $\mathrm{Al}$ & & 1 & 4 & 12 \\
\hline $\mathrm{H}+\mathrm{Al}$ & & 31 & 38 & 88 \\
\hline SB & & 55,7 & 7,3 & 9,6 \\
\hline CTC & & 86,7 & 45,3 & 97,6 \\
\hline $\mathrm{V}$ & \multirow{2}{*}{$\%$} & 64 & 16 & 10 \\
\hline Sat. Al & & 2 & 35 & 56 \\
\hline $\mathrm{S}$ & \multirow{6}{*}{ 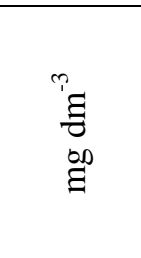 } & 8 & 11 & 20 \\
\hline $\mathrm{Cu}$ & & 3,0 & 0,2 & 27,0 \\
\hline $\mathrm{Fe}$ & & 202,0 & 222,0 & 238,0 \\
\hline $\mathrm{Zn}$ & & 1,0 & 0,6 & 1,0 \\
\hline $\mathrm{Mn}$ & & 34,0 & 6,0 & 37,0 \\
\hline B & & 0,61 & 0,55 & 0,48 \\
\hline Areia & \multirow{4}{*}{$\%$} & 53 & 92 & 38 \\
\hline Silte & & 30 & 5 & 41 \\
\hline Argila & & 17 & 3 & 21 \\
\hline Textura & & $\begin{array}{l}\text { Média- } \\
\text { arenosa }\end{array}$ & Arenosa & Média-arenosa \\
\hline
\end{tabular}

O manejo da irrigação foi realizado seguindo o método de irrigação por inundação contínua ou permanente, em que a água é introduzida na lavoura formando uma lâmina sobre a superfície do solo e essa lâmina é mantida até a sua retirada próximo a maturação fisiológica dos grãos (FORNASIERI FILHO; FORNASIERI, 2006).

As condições de temperatura e umidade durante a condução do experimento em cada local foram obtidas por meio dos registros das estações meteorológicas localizadas mais próximas ao local do experimento. A temperatura média e umidade relativa média durante o período de condução dos experimentos foram: $22,9^{\circ} \mathrm{C}$ e $82,8 \% ; 24,6^{\circ} \mathrm{C}$ e $77,1 \%$; e $22,1^{\circ} \mathrm{C}$ e $77,6 \%$, para a Granja Quatro Irmãos, Fazenda Pitangueiras e Estação Experimental Barragem Capané, respectivamente (INSTITUTO NACIONAL DE METEOROLOGIA, 2013).

O delineamento experimental utilizado nas três localidades foi o de blocos ao acaso, com nove tratamentos (Tabela 2) e quatro repetições. Com exceção da testemunha, todos os tratamentos receberam aplicações de Ajifol + Amino Plus no início do perfilhamento e posteriormente, de Ajifol K em épocas distintas, ou seja, no início da formação do primórdio floral, no emborrachamento e no início do florescimento, de acordo com o apresentado na Tabela 2. 
Tabela 2. Tratamentos avaliados.

\begin{tabular}{lccc}
\hline \multicolumn{1}{c}{$1^{\mathrm{a}}$} & APLICAÇÕES & & $4^{\mathrm{a}}$ \\
\hline 01. TESTEMUNHA & $2^{\mathrm{a}}$ & - & - \\
02. AJIFOL + AMINO PLUS & - & - & - \\
03. AJIFOL + AMINO PLUS & AJIFOL K & AJIFOL K & AJIFOL K \\
04. AJIFOL + AMINO PLUS & AJIFOL K & AJIFOL K & - \\
05. AJIFOL + AMINO PLUS & AJIFOL K & - & AJIFOL K \\
06. AJIFOL + AMINO PLUS & - & AJIFOL K & AJIFOL K \\
07. AJIFOL + AMINO PLUS & AJIFOL K & - & - \\
08. AJIFOL + AMINO PLUS & - & AJIFOL K & - \\
09. AJIFOL + AMINO PLUS & - & - & AJIFOL K
\end{tabular}

$1^{\text {a }}$ - Aplicação no início do perfilhamento (15 dias após a emergência - DAE em Rio Grande e Cidreira, e aos 16 DAE em Cachoeira do Sul)

$2^{\mathrm{a}}$ - Aplicação no início da formação do primórdio floral (41 DAE em Rio Grande, 43 DAE em Cidreira e 49 DAE em Cachoeira do Sul)

$3^{\mathrm{a}}$ - Aplicação no emborrachamento (87 DAE em Rio Grande, 75 DAE em Cidreira e 79 DAE em Cachoeira do Sul)

$4^{\mathrm{a}}$ - Aplicação no início do florescimento (98 DAE em Rio Grande, 87 DAE em Cidreira e 91 DAE em Cachoeira do Sul)

O Ajifol contém $10 \%$ de nitrogênio $(\mathrm{N}), 2 \%$ de óxido de potássio $\left(\mathrm{K}_{2} \mathrm{O}\right), 5 \%$ de zinco $(\mathrm{Zn}), 2 \%$ de manganês (Mn), $1 \%$ de boro (B), 6\% de enxofre (S) e 30\% de matéria orgânica. O Amino Plus possui $11 \%$ de nitrogênio $(\mathrm{N}), 1 \%$ de óxido de potássio $\left(\mathrm{K}_{2} \mathrm{O}\right)$ e $30 \%$ de matéria orgânica. Por sua vez, o Ajifol K apresenta $25 \%$ de óxido de potássio $\left(\mathrm{K}_{2} \mathrm{O}\right)$ e $3 \%$ de TOC (Carbono Orgânico Total).

As doses dos produtos utilizados foram as seguintes: Amino Plus - 0,5 L P.C./ha; Ajifol - 1,0 L P.C./ha e Ajifol K - no total 3,0 L P.C. / ha (sendo dividida em partes iguais de acordo com o número de aplicações).

Na Granja Quatro Irmãos (GQI) foi utilizado o cultivar IRGA 424 e as parcelas foram constituídas por 18 linhas de plantas de arroz, com $7 \mathrm{~m}$ de comprimento, espaçadas de $0,17 \mathrm{~m}$, apresentando área total de 21,42 $\mathrm{m}^{2}$. A semeadura foi realizada no dia 26/10/2009 com uma densidade de 80 sementes por metro e a emergência ocorreu 13 dias após (08/11/2009). A adubação de base constou da aplicação aos 15 dias antecedendo a semeadura, do equivalente a $130 \mathrm{~kg}$ de superfosfato triplo por hectare. Por ocasião da semeadura, aplicou-se a lanço o equivalente a $250 \mathrm{~kg} / \mathrm{ha}$ de cloreto de potássio. Foram realizadas duas adubações em cobertura aos $20 \mathrm{e}$ 41 dias após a emergência (DAE), aplicando-se respectivamente o equivalente a $200 \mathrm{~kg} / \mathrm{ha}$ e $80 \mathrm{~kg} / \mathrm{ha}$ de ureia. Imediatamente após a primeira adubação de cobertura, procedeu-se a inundação das parcelas. Para o controle das doenças comuns à cultura, as sementes foram tratadas com o fungicida Derosal Plus (Carbendazim) na dose de $200 \mathrm{~mL}$ P.C./100 kg de sementes (30 gramas i.a./100 kg de sementes), e foi aplicado aos 87 e 98 DAE, o fungicida Brio (Epoxiconazol + Cresoxim-metílico) na dose de $750 \mathrm{~mL}$ P.C./ha $(93,75$ + 93,75 g i.a./ha), adicionado do óleo mineral Assist na dose de $500 \mathrm{~mL}$ P.C./ha visando o controle da mancha parda. Para o controle das pragas comuns à cultura, as sementes foram tratadas com o inseticida Standak (Fipronil) na dose de $80 \mathrm{~mL}$ P.C. $/ 100 \mathrm{~kg}$ de sementes (10 g i.a./100 kg de sementes). As plantas daninhas foram controladas através da aplicação por ocasião da semeadura, da mistura dos herbicidas Gamit (Clomazona) + Roundup Original (Glifosato) na dose de 0,80 + 2,50 L P.C./ha $(400+1.200$ g i.a./ha), e da aplicação aos 17 DAE da cultura, do herbicida Ricer (Penoxsulam) na dose de $180 \mathrm{~mL}$ P.C./ha (43,20 g i.a./ha).

Na Fazenda Pitangueiras (FZP) foi utilizado o cultivar Puitá INTA CL e as parcelas apresentaram dimensões semelhantes à GQI. A semeadura foi realizada no dia 29 de outubro de 2009, com uma densidade de 70 sementes por metro e a emergência ocorreu seis dias após (04/11/2009). A adubação mineral de base constou da aplicação por ocasião da semeadura, do equivalente a $350 \mathrm{~kg} / \mathrm{ha}$ da fórmula 08-23-30. Aos 32 DAE, Foi realizada uma adubação em cobertura, aplicando-se o equivalente a $180 \mathrm{~kg} / \mathrm{ha}$ de ureia e aos 33 DAE 
procedeu-se a inundação das parcelas. Para o controle das doenças comuns à cultura, foi aplicado aos 75 e 87 DAE o fungicida BRIO (Epoxiconazol + Cresoxim-metílico) na dose de $750 \mathrm{~mL}$ P.C./ha $(93,75+93,75 \mathrm{~g}$ i.a./ha), adicionado do óleo mineral Assist na dose de 0,50 L P.C./ha. Para o controle das pragas comuns à cultura, as sementes foram tratadas com o inseticida Standak (Fipronil) na dose de $200 \mathrm{~mL}$ P.C./100 kg de sementes (50 g i.a./100 kg de sementes), e aos $32 \mathrm{DAE}$, foi aplicado o inseticida Talcord (Permetrina) na dose de $80 \mathrm{~mL}$ P.C./ha (20 g i.a./ha). As plantas daninhas foram controladas através da aplicação aos 19 e 32 DAE, do herbicida Only (Imazetapir + Imazapique) na dose de 0,80 L P.C./ha $(60+20$ g i.a./ha respectivamente), adicionado do espalhante adesivo Dash na dose de $150 \mathrm{~mL}$ P.C./ha.

Na Estação Experimental Barragem Capané (EEBC) foi utilizado o cultivar IRGA 417, a semeadura realizada em 23/10/2009, com uma densidade de 70 sementes por metro. As parcelas foram constituídas por 19 linhas de plantas de arroz, com $7 \mathrm{~m}$ de comprimento, espaçadas de $0,155 \mathrm{~m}$, apresentando área de $20,61 \mathrm{~m}^{2}$. A emergência ocorreu nove dias após a semeadura (01/11/2009). Na adubação de semeadura utilizou-se 350 $\mathrm{kg} / \mathrm{ha}$ da fórmula 05-20-30. Foram realizadas duas adubações em cobertura, aos 17 e 50 DAE, aplicando-se respectivamente o equivalente a $180 \mathrm{~kg} / \mathrm{ha}$ e $90 \mathrm{~kg} / \mathrm{ha}$ de ureia. Procedeu-se a inundação das parcelas imediatamente após a primeira adubação em cobertura. Para o controle das doenças comuns à cultura, foi aplicado aos 70 DAE, o fungicida Brio (Epoxiconazol + Cresoxim-metílico) na dose de $750 \mathrm{~mL}$ P.C./ha (93,75 + 93,75 g i.a./ha). Para o controle das pragas comuns à cultura, foi aplicado aos 70 DAE, o inseticida Actara $250 \mathrm{WG}$ (Tiametoxan) na dose de $200 \mathrm{~g}$ P.C./ha (50 g i.a./ha). As plantas daninhas foram controladas através da aplicação do herbicida Ricer (Penoxsulam) na dose de 1,0 L P.C./ha (240 g i.a./ha), adicionado do óleo vegetal Natur'l Óleo na dose de 1,0 L P.C./ha.

Na primeira aplicação dos fertilizantes foliares foi utilizado um pulverizador costal motorizado da marca Yamaho, modelo LS 937, dotado de uma barra pulverizadora com seis bicos jato plano de uso ampliado XR Teejet 110.04VS, numa pressão constante de $30 \mathrm{lb} / \mathrm{pol}^{2}$, com um gasto de calda equivalente a $500 \mathrm{~L} / \mathrm{ha} . \mathrm{Na}$ segunda, terceira e quarta aplicações foi utilizado um pulverizador costal a gás carbônico, dotado de uma barra pulverizadora com seis bicos jato plano de uso ampliado XR Teejet 110.04VS, numa pressão constante de 30 $\mathrm{lb} / \mathrm{pol}^{2}$, com um gasto de calda equivalente a $500 \mathrm{~L} / \mathrm{ha}$. As condições climáticas e do solo nos dias das aplicações dos tratamentos estavam favoráveis e encontram-se na Tabela 3.

Tabela 3. Condições climáticas e do solo nos dias das aplicações dos tratamentos.

\begin{tabular}{lccccc}
\hline Aplicações & $\begin{array}{c}\text { Temperatura } \\
\left({ }^{\mathbf{O}} \mathbf{C}\right)\end{array}$ & $\begin{array}{c}\text { Umidade Relativa do } \\
\mathbf{a r}(\boldsymbol{\%})\end{array}$ & $\begin{array}{c}\text { Velocidade do } \\
\text { vento }(\mathbf{k m} / \mathbf{h})\end{array}$ & $\begin{array}{c}\text { Umidade } \\
\text { do Solo }\end{array}$ \\
\hline Granja & $\mathbf{1}^{\mathbf{a}}$ & 25 & 60 & 6,0 & saturado \\
Quatro & $\mathbf{2}^{\mathbf{a}}$ & 29 & 61 & 6,0 & inundado \\
Irmãos & $\mathbf{3}^{\mathbf{a}}$ & 29 & 80 & 6,5 & inundado \\
& $\mathbf{4}^{\mathbf{a}}$ & 27 & 83 & 5,7 & inundado \\
Fazenda & $\mathbf{1}^{\mathbf{a}}$ & 34 & 73 & 4,5 & saturado \\
Pitangueiras & $\mathbf{2}^{\mathbf{a}}$ & 28 & 62 & 2,0 & inundado \\
& $\mathbf{3}^{\mathbf{a}}$ & 27 & 71 & 3,2 & inundado \\
& $\mathbf{4}^{\mathbf{a}}$ & 34 & 68 & 0,0 & inundado \\
Estação & $\mathbf{1}^{\mathbf{a}}$ & 27 & 55 & 4,8 & saturado \\
Experimental & $\mathbf{2}^{\mathbf{a}}$ & 30 & 65 & 0,0 & inundado \\
Barragem & $\mathbf{3}^{\mathbf{a}}$ & 29 & 65 & 2,0 & inundado \\
Capané & $\mathbf{4}^{\mathbf{a}}$ & 30 & 70 & 0,0 & inundado \\
\hline
\end{tabular}

Os seguintes parâmetros foram avaliados: "comprimento das panículas" em centímetros (CP), "número de espiguetas por panícula" (NE); "número de grãos cheios por panícula" (NGC); "porcentagem de esterilidade de espiguetas" (PE) e "peso de 1.000 grãos, em gramas" (PMG), amostrando-se aleatoriamente dez panículas por parcela. Nestas mesmas datas foi avaliado o rendimento de grãos (R), procedendo-se a colheita de $5,0 \mathrm{~m}^{2}$ 
centrais de cada parcela, sendo os dados transformados e apresentados em $\mathrm{kg} / \mathrm{ha}$ a $13 \%$ de umidade.

Para a análise de variância, todos os dados foram transformados em $\sqrt{ }(\mathrm{x})$, com exceção dos dados de "porcentagem de esterilidade" que foram transformados em ângulos correspondentes ao arc sen porcentagem.

Os resultados foram analisados segundo o teste de Tukey, ao nível de $5 \%$ de probabilidade.

\section{RESULTADOS E DISCUSSÃO}

Os dados referentes a temperatura durante a realização do experimento encontram-se na Tabela 4.

Tabela 4. Temperatura média durante os estádios de desenvolvimento do arroz.

\begin{tabular}{lcccc}
\hline \multirow{2}{*}{ Estádios Fenológicos } & \multicolumn{4}{c}{ Temperatura $\left({ }^{\mathbf{0}} \mathbf{C}\right)$} \\
& Ideal* & GQI & FZP & EEBC \\
\hline Perfilhamento & $25-31$ & 21,0 & 22,6 & 20,6 \\
Primórdio Floral & $25-30$ & 24,5 & 25,5 & 23,3 \\
Emborrachamento & $25-28$ & 26,7 & 24,9 & 22,7 \\
Início do Florescimento & $30-33$ & 24,5 & 29,0 & 26,3 \\
\hline Média Total do Ciclo & $25-35$ & 22,9 & 24,6 & 22,1 \\
\hline
\end{tabular}

* Dados da Embrapa (2005).

A colheita foi realizada aos 142, 115 e 117 DAE na Granja Quatro Irmãos, Fazenda Pitangueiras e Estação Experimental Barragem Capané, respectivamente. O comprimento das panículas e o número de espiguetas por panículas não sofreram interferência dos tratamentos avaliados (Tabela 5). Em termos médios, o comprimento das panículas foi de 22,4, 20,7 e 23,3 cm para os cultivares IRGA 424 (GQI), Puitá INTA CL (FZP) e IRGA 417 (EEBC), respectivamente; enquanto que o número de espiguetas por panícula foi de 124,7, 96,0 e 116,4, para os mesmos cultivares e locais descritos anteriormente. Zaratin et al. (2004) estudando o efeito de quatro níveis de potássio $\left(0,20,30\right.$ e $40 \mathrm{~kg} / \mathrm{ha}$ de $\left.\mathrm{K}_{2} \mathrm{O}\right)$ aplicados no solo em seis cultivares de arroz de sequeiro favorecido obtiveram aumentos no comprimento de panículas e no número de espiguetas por panículas com as maiores doses de potássio.

Tabela 5. "Comprimento de panículas" em centímetros (CP) e "número de espiguetas por panícula" (NE) de arroz na Granja Quatro Irmãos (GQI), Fazenda Pitangueiras (FZP) e Estação Experimental Barragem do Capané (EEBC).

\begin{tabular}{lcccccc}
\hline \multirow{2}{*}{ TRATAMENTOS $^{(\mathbf{1})}$} & \multicolumn{3}{c}{ CP* $^{*}$} & & \multicolumn{3}{c}{ NE* $^{*}$} \\
\cline { 2 - 7 } & GQI & FZP & EEBC & GQI & FZP & EEBC \\
\hline 01 & $22,42 \mathrm{a}^{* *}$ & $20,59 \mathrm{a}$ & $23,15 \mathrm{a}$ & $124,35 \mathrm{a}$ & $95,50 \mathrm{a}$ & $116,80 \mathrm{a}$ \\
02 & $22,80 \mathrm{a}$ & $20,93 \mathrm{a}$ & $23,07 \mathrm{a}$ & $125,93 \mathrm{a}$ & $94,95 \mathrm{a}$ & $114,68 \mathrm{a}$ \\
03 & $22,87 \mathrm{a}$ & $20,91 \mathrm{a}$ & $23,49 \mathrm{a}$ & $129,65 \mathrm{a}$ & $96,73 \mathrm{a}$ & $117,85 \mathrm{a}$ \\
04 & $22,69 \mathrm{a}$ & $21,23 \mathrm{a}$ & $23,60 \mathrm{a}$ & $128,28 \mathrm{a}$ & $104,75 \mathrm{a}$ & $118,75 \mathrm{a}$ \\
05 & $22,67 \mathrm{a}$ & $20,93 \mathrm{a}$ & $23,15 \mathrm{a}$ & $118,88 \mathrm{a}$ & $92,58 \mathrm{a}$ & $119,45 \mathrm{a}$ \\
06 & $22,69 \mathrm{a}$ & $20,86 \mathrm{a}$ & $23,57 \mathrm{a}$ & $126,35 \mathrm{a}$ & $97,55 \mathrm{a}$ & $118,85 \mathrm{a}$ \\
07 & $22,43 \mathrm{a}$ & $20,45 \mathrm{a}$ & $22,68 \mathrm{a}$ & $122,43 \mathrm{a}$ & $90,88 \mathrm{a}$ & $107,70 \mathrm{a}$ \\
08 & $22,23 \mathrm{a}$ & $20,46 \mathrm{a}$ & $23,45 \mathrm{a}$ & $124,93 \mathrm{a}$ & $97,10 \mathrm{a}$ & $115,80 \mathrm{a}$ \\
09 & $21,29 \mathrm{a}$ & $20,39 \mathrm{a}$ & $23,60 \mathrm{a}$ & $121,25 \mathrm{a}$ & $94,08 \mathrm{a}$ & $117,43 \mathrm{a}$ \\
\hline $\mathrm{CV}(\%)$ & 2,70 & 1,01 & 1,72 & 4,27 & 3,28 & 4,45 \\
\hline
\end{tabular}

(1) Os tratamentos, doses e respectivas épocas de aplicações são descritos na Tabela 1.

*Para a análise de variância, os dados foram transformados em $\sqrt{(\mathrm{x}) .}$ **Médias seguidas da mesma letra não diferem estatisticamente pelo teste de Tukey, ao nível de 5\% de probabilidade. 
O número de grãos cheios e a porcentagem de esterilidade de espiguetas por panícula também não foram afetados pelos tratamentos avaliados (Tabela 6). Estes dados divergem de Zaratin et al. (2004) que obtiveram acréscimos nestes parâmetros com o aumento de doses de potássio no solo em arroz de sequeiro favorecido. Por sua vez, Camargo et al. (2008) avaliando doze produtos foliares aplicados no estádio de emborrachamento de arroz irrigado, dentre eles o Supa-potássio®, não observaram influência sobre número de grãos por panícula e na porcentagem de esterilidade de espiguetas. A mesma resposta foi obtida por Marchezan, Camargo e Segabinazzi (2007), que combinando épocas de aplicação e incorporação ou não de fertilizantes fosfatados e potássicos não observaram interferência sobre os dois parâmetros.

Em termos médios, o cultivar IRGA 424 (GQI) apresentou 113,4 grãos cheios por panícula, enquanto os cultivares Puitá INTA CL (FZP) e IRGA 417 (EEBC) atingiram 84,0 e 108,8 grãos cheios por panícula, respectivamente. Quanto à porcentagem de esterilidade (Tabela 6), os cultivares IRGA 424 e IRGA 417 estiveram abaixo da média relatada por Sementes Simão (2012) entre 15-25\% e 10\%, atingindo 9,0\% e 5,7\%, respectivamente. Já para o cultivar Puitá INTA CL, a PE foi de 12,5\%, superando um pouco o valor de $10 \%$ descrito pelo mesmo autor, o que de forma geral, indica que as condições foram favoráveis à produção de grãos nas três localidades estudadas.

Tabela 6. "Número de grãos cheios por panícula" (NGC) e "porcentagem de esterilidade" (PE) de arroz na Granja Quatro Irmãos (GQI), Fazenda Pitangueiras (FZP) e Estação Experimental Barragem do Capané (EEBC).

\begin{tabular}{|c|c|c|c|c|c|c|}
\hline \multirow{2}{*}{ TRATAMENTOS $^{(1)}$} & \multicolumn{3}{|c|}{ NGC* } & \multicolumn{3}{|c|}{$\mathrm{PE}^{* * *}$} \\
\hline & GQI & FZP & EEBC & GQI & FZP & EEBC \\
\hline 01 & $112,95 a^{* * *}$ & $84,68 \mathrm{a}$ & $110,43 a$ & $9,12 \mathrm{a}$ & $11,29 a$ & $5,42 \mathrm{a}$ \\
\hline 02 & $112,98 \mathrm{a}$ & $83,13 a$ & $108,38 \mathrm{a}$ & $10,31 \mathrm{a}$ & $12,37 \mathrm{a}$ & $5,48 \mathrm{a}$ \\
\hline 03 & $116,48 \mathrm{a}$ & $83,95 \mathrm{a}$ & $110,00 \mathrm{a}$ & $10,03 a$ & $13,20 \mathrm{a}$ & $6,65 \mathrm{a}$ \\
\hline 04 & $116,38 \mathrm{a}$ & $91,28 \mathrm{a}$ & $111,05 \mathrm{a}$ & $9,30 \mathrm{a}$ & $12,94 \mathrm{a}$ & $6,45 \mathrm{a}$ \\
\hline 05 & $109,28 \mathrm{a}$ & $79,08 \mathrm{a}$ & $104,68 \mathrm{a}$ & $8,00 \mathrm{a}$ & $14,61 \mathrm{a}$ & $5,23 \mathrm{a}$ \\
\hline 06 & $117,35 \mathrm{a}$ & $85,23 \mathrm{a}$ & $112,45 \mathrm{a}$ & $7,14 \mathrm{a}$ & $12,53 a$ & $5,44 \mathrm{a}$ \\
\hline 07 & $111,73 a$ & $80,60 \mathrm{a}$ & $101,38 \mathrm{a}$ & $8,73 \mathrm{a}$ & $11,20 \mathrm{a}$ & $5,78 \mathrm{a}$ \\
\hline 08 & $113,00 \mathrm{a}$ & $85,33 a$ & $110,13 \mathrm{a}$ & $9,58 \mathrm{a}$ & $12,14 \mathrm{a}$ & $4,90 \mathrm{a}$ \\
\hline 09 & $110,58 \mathrm{a}$ & $82,50 \mathrm{a}$ & $110,83 \mathrm{a}$ & $8,91 \mathrm{a}$ & $12,37 \mathrm{a}$ & $5,58 \mathrm{a}$ \\
\hline $\mathrm{CV}(\%)$ & 4,48 & 3,48 & 4,36 & 7,67 & 8,34 & 12,61 \\
\hline
\end{tabular}

(1) Os tratamentos, doses e respectivas épocas de aplicações são descritos na Tabela 1.

*Para a análise de variância, os dados foram transformados em $\sqrt{(\mathrm{x})}$.**Para a análise de variância, os dados foram transformados em ângulos correspondentes ao arc sen porcentagem. *** Médias seguidas da mesma letra não diferem estatisticamente pelo teste de Tukey, ao nível de 5\% de probabilidade.

O peso de 1000 grãos dos cultivares IRGA 424 e Puitá INTA CL não foi afetado significativamente pelos produtos utilizados, apenas o cultivar IRGA 417 com os tratamentos 7 e 8 superou significativamente o tratamento 2 (Tabela 7). O peso médio de 1000 grãos foi de 26,1, 25,9 e 28,7 g para os cultivares IRGA 424, Puitá INTA CL e IRGA 417, respectivamente, superando os valores de 25,5, 25,7 e 27,6 g relatados por Sementes Simão (2012), caracterizando as boas condições edafoclimáticas, fitossanitárias e nutricionais dos três locais de estudo. Camargo et al. (2008) também não obtiveram diferenças na massa de mil grãos quando testaram a aplicação de diversos produtos foliares, do mesmo modo que Marchezan, Camargo e Segabinazzi (2007) não verificaram interferência variando o momento e o modo de realização da adubação potássica.

Quanto ao rendimento de grãos (Tabela 7), não houve interferência dos tratamentos para os cultivares IRGA 424 semeado na Granja Quatro Irmãos e IRGA 417 semeado na Estação Experimental Barragem 
Capané, alcançando 11.910 e $15.036 \mathrm{~kg} / \mathrm{ha}$, respectivamente, o que pode ser explicado pelo alto teor de $\mathrm{K}$ disponível no solo, de 1,7 e 1,6 $\mathrm{mmol}_{\mathrm{c}} \mathrm{dm}^{-3}$ (Tabela 1), respectivamente, já que o teor considerado bom é de 1,5 mmol $_{\mathrm{c}} \mathrm{dm}^{-3}$ segundo o IRGA (2001) e de $1,3 \mathrm{mmol}_{\mathrm{c}} \mathrm{dm}^{-3}$ para Fageria (2006). De acordo com Scivittaro e Gomes (2007) a resposta do arroz irrigado à adubação potássica normalmente é baixa, mesmo em solos com teores baixo ou médio de potássio disponível.

Por sua vez, para o cultivar Puitá INTA CL semeado na Fazenda Pitangueiras, cuja média foi de 9.778 $\mathrm{kg} / \mathrm{ha}$, o tratamento 4 superou estatisticamente os tratamentos 5, 7 e 9, não diferindo, porém, dos demais (Tabela 7). Neste solo, o teor de K disponível era de $1,3 \mathrm{mmol}_{\mathrm{c}} \mathrm{dm}^{-3}$, inferior ao recomendado pelo IRGA (2001) e igual ao mínimo de acordo com Fageria (2006).

Como as condições climáticas nessas localidades foram bem próximas, supõe-se que a interferência das épocas de aplicação foliar de potássio na Fazenda Pitangueiras deve-se a cultivar, já que de acordo com Embrapa (2005), a temperatura ótima para o desenvolvimento do arroz situa-se entre 20 e $35^{\circ} \mathrm{C}$ (Tabela 4).

De qualquer forma, nas três localidades, as produtividades foram bem elevadas quando comparadas à média das lavouras gaúchas de $7.412 \mathrm{~kg} / \mathrm{ha}$ na safra 2010/11 (CONAB, 2011).

Estes dados não corroboram com as observações de Zaratin et al. (2004) que avaliando a influência de potássio aplicado na semeadura e no início do florescimento, obtiveram acréscimos sobre o peso de 1000 grãos e no rendimento de grãos de arroz de sequeiro favorecido, mostrando o efeito benéfico deste nutriente. Maiores rendimentos de grãos também foram obtidos por Fageria (1991) com o parcelamento de $\mathrm{K} \mathrm{em}$ arroz de sequeiro e irrigado, em solos dos grupos oxissolo e hidromórfico, com a aplicação de $60 \mathrm{~kg} / \mathrm{ha}$ de $\mathrm{K}_{2} \mathrm{O}$, parcelada em quantidades iguais na semeadura, na diferenciação do primórdio floral e na floração, e também com apenas 30 $\mathrm{kg} / \mathrm{ha}$ de $\mathrm{K}_{2} \mathrm{O}$ aplicados na diferenciação do primórdio floral. Lopes et al. (1995) verificaram maior eficiência de utilização de $\mathrm{K}$ aplicado por ocasião da semeadura que quando parcelado, onde em cultivos sucessivos de arroz irrigado na mesma área, a dose para manter os rendimentos máximos mostrou tendência de estabilizar-se em torno de 70 a $80 \mathrm{~kg} / \mathrm{ha}$ de $\mathrm{K}_{2} \mathrm{O}$.

Por outro lado, resultados divergentes foram obtidos por Knoblauch, Bacha e Stuker (2007) que, testando doses de 0 a $240 \mathrm{~kg} / \mathrm{ha}$ de $\mathrm{K}_{2} \mathrm{O}$ em solo com teor de $\mathrm{K}$ disponível de $80 \mathrm{mg} \mathrm{dm}^{-3}$, não tiveram aumento significativo de rendimento em áreas já cultivadas no sistema pré-germinado e por Genro Júnior et al. (2007), que testando doses de 0 a $180 \mathrm{~kg} / \mathrm{ha}$ de $\mathrm{K}_{2} \mathrm{O}$ também não atingiram resposta significativa. Para as duas situações, segundo Barberena (2009), é provável que acima de $80 \mathrm{mg} \mathrm{dm}^{-3}$ de $\mathrm{K}$ disponível não haja resposta significativa do arroz ao uso de adubação potássica. Além desses, Lopes (1991), Eberhardt, Bacha e Stucker (1995), Machado e Franco (1995), Marchezan, Camargo e Segabinazzi (2007), Camargo et al. (2008) e Barberena (2009) também não obtiveram respostas no rendimento de grãos de arroz com a adição e o parcelamento de potássio no solo.

Tabela 7. "Peso de 1.000 grãos em gramas" (PMG) e "rendimento de grãos" (R) em kg/ha de arroz na Granja Quatro Irmãos (GQI), Fazenda Pitangueiras (FZP) e Estação Experimental Barragem do Capané (EEBC) de acordo com o tratamento avaliado.

(Continua)

\begin{tabular}{lcccccc}
\hline \multirow{2}{*}{ TRATAMENTOS $^{(\mathbf{1})}$} & \multicolumn{3}{c}{ PMG* $^{*}$} & \multicolumn{3}{c}{ R* $^{*}$} \\
\cline { 2 - 7 } & GQI & FZP & EEBC & GQI & FZP & EEBC \\
\hline 01 & $25,94 \mathrm{a}^{* *}$ & $25,74 \mathrm{a}$ & $28,75 \mathrm{ab}$ & $11.810 \mathrm{a}$ & $9.800 \mathrm{ab}$ & $15.075 \mathrm{a}$ \\
02 & $26,00 \mathrm{a}$ & $26,07 \mathrm{a}$ & $28,01 \mathrm{~b}$ & $11.826 \mathrm{a}$ & $9.746 \mathrm{ab}$ & $14.418 \mathrm{a}$ \\
03 & $25,97 \mathrm{a}$ & $26,25 \mathrm{a}$ & $28,29 \mathrm{ab}$ & $12.194 \mathrm{a}$ & $9.854 \mathrm{ab}$ & $15.596 \mathrm{a}$ \\
04 & $25,75 \mathrm{a}$ & $26,14 \mathrm{a}$ & $28,44 \mathrm{ab}$ & $12.082 \mathrm{a}$ & $10.736 \mathrm{a}$ & $15.455 \mathrm{a}$ \\
05 & $25,95 \mathrm{a}$ & $25,28 \mathrm{a}$ & $29,00 \mathrm{ab}$ & $11.432 \mathrm{a}$ & $8.977 \mathrm{~b}$ & $14.954 \mathrm{a}$
\end{tabular}

Nucleus, v.10, n.1, abr.2013 
Tabela 7. "Peso de 1.000 grãos em gramas" (PMG) e "rendimento de grãos" (R) em kg/ha de arroz na Granja Quatro Irmãos (GQI), Fazenda Pitangueiras (FZP) e Estação Experimental Barragem do Capané (EEBC) de acordo com o tratamento avaliado.

(Conclusão)

\begin{tabular}{|c|c|c|c|c|c|c|}
\hline 06 & $26,29 a$ & $26,05 \mathrm{a}$ & $28,49 \mathrm{ab}$ & $12.440 \mathrm{a}$ & 9.991ab & $15.207^{\mathrm{a}}$ \\
\hline 07 & $26,23 a$ & $25,90 \mathrm{a}$ & $29,52 \mathrm{a}$ & $11.810 \mathrm{a}$ & $9.387 \mathrm{~b}$ & $14.221 \mathrm{a}$ \\
\hline 08 & $26,26 a$ & $25,90 \mathrm{a}$ & $29,60 \mathrm{a}$ & $11.953 \mathrm{a}$ & 9.942ab & $15.482 \mathrm{a}$ \\
\hline 09 & $26,11 \mathrm{a}$ & $25,72 \mathrm{a}$ & $28,33 \mathrm{ab}$ & $11.643 \mathrm{a}$ & $9.567 \mathrm{~b}$ & $14.915 \mathrm{a}$ \\
\hline $\mathrm{CV}(\%)$ & 1,03 & 1,05 & 0,95 & 4,71 & 2,26 & 6,26 \\
\hline
\end{tabular}

\section{CONCLUSÃO}

A aplicação foliar de potássio em diversos estádios fenológicos da cultura do arroz irrigado não interfere nos componentes de produção dos cultivares IRGA 424, Puitá INTA CL e IRGA 417 e no rendimento de grãos dos cultivares IRGA 424 e IRGA 417. A aplicação foliar de potássio no perfilhamento, início da formação do primórdio floral e no estádio de emborrachamento proporciona maior rendimento da cultivar Puitá INTA CL.

\section{REFERÊNCIAS}

AJINOMOTO, FERTILIZANTES. Ajifol Potássio. Disponível em:

<http://www.rudalov.com/clientes/ew/ajinomoto/produtos/fertilizantes-foliares/ajifol-potassio/>. Acesso em 20 dez. 2011.

BARBERENA, D.S. Efeitos de doses de fósforo e de potássio no arroz irrigado em várzea de Roraima. 2009. 70f. Dissertação (Mestrado em Produção Vegetal) - Curso de Pós-graduação em Agronomia, Universidade Federal de Roraima, Boa Vista.

BARBOSA FILHO, M.P. Calagem e Adubação. In: STONE, L.F. et al. (Eds.) Arroz: o produtor pergunta, a Embrapa responde. Brasília: Embrapa Arroz e Feijão: Embrapa Informação Tecnológica, 2001. p. 35-71.

BORKERT, C. M. Soja: adubação foliar. Londrina: EMBRAPA-CNPSo, 1987. 34 p. (Documentos, 22).

CAMARGO, E.R.et al. Manutenção da área foliar e produtividade de arroz irrigado com a aplicação de fertilizantes foliares no estádio de emborrachamento. Ciência Rural, Santa Maria, v.38, n.5, p. 1439-1442, 2008.

CONAB, COMPANHIA NACIONAL DE ABASTECIMENTO. Dados preliminares da safra de arroz 2010/2011. (Séries Históricas). Disponível em: $\langle$ http://www.conab.gov.br/conteudos.php?a=1252\&t=2>. Acesso em: 21 jan. 2012.

EBERHARDT, D.S.; BACHA, R.E.; STUCKER, H. Níveis de nitrogênio e potássio para adubação do arroz irrigado, sistema pré-germinado. In: REUNIÃO DA CULTURA DO ARROZ IRRIGADO, 21, 1995, Porto Alegre. Anais... Porto Alegre: IRGA, 1995. p.180-183.

EMBRAPA - Empresa Brasileira de Pesquisa Agropecuária. Condições climáticas para o cultivo do arroz no Brasil. 2005. Disponível em:

<http://sistemasdeproducao.cnptia.embrapa.br/FontesHTML/Arroz/ArrozIrrigadoBrasil/cap02.htm> Acesso em: 10 abr. 2013. 
FAGERIA, N.K. Adubação e Calagem. In: SANTOS, A.B.; STONE, L.F.; VIEIRA, N.R.A. (Ed.). A Cultura do arroz no Brasil. 2.ed. Santo Antônio de Goiás: Embrapa Arroz e Feijão, 2006. p.425-450.

FAGERIA, N.K. Response of rice to fractional applied potassium in Brazil. Better Crops International, Norcross, v.7, n.2, 1991. p.19.

FAQUIN, V. Nutrição mineral de plantas. Lavras: UFLA, FAEOE, 2005. 183 p.

FORNASIERI FILHO, D.; FORNASIERI, J.L. Manual da cultura do arroz. Jaboticabal: Funep, 2006. 589p.

GENRO JR., S.A.et al. Resposta do arroz irrigado à aplicação de doses de potássio em solos com diferentes CTCs. In: CONGRESSO BRASILEIRO DE ARROZ IRRIGADO, 5.; REUNIÃO DA CULTURA DO ARROZ IRRIGADO, 27, 2007, Pelotas. Anais... Pelotas: EMBRAPA, 2007. p.583-585.

HE, H.et al. Fertility behaviour of rice (Oryza sativa) lines with dominant male sterile gene and inheritance of sterility and fertility restoration. Field Crops Research, Amsterdam, v.98, n.1, p.30-38, 2006.

INSTITUTO NACIONAL DE METEOROLOGIA - INMET. Banco de Dados Meteorológicos para Ensino e Pesquisa. (Dados históricos) Disponível em: 〈http://www.inmet.gov.br/portal/index.php?r=bdmep/bdmep $>$ Acesso em: 9 abr. 2013.

IRGA- Instituto Rio Grandense do Arroz. Recomendações Técnicas da Pesquisa para o Sul do Brasil. Porto Alegre: IRGA, 2001. 128p.

KNOBLAUCH, R.; BACHA, R.E.; STUKER, H. Níveis de nitrogênio e potássio para adubação do arroz irrigado em sistema de pré-germinado. In: REUNIÃO DA CULTURA DO ARROZ IRRIGADO, 27, 2007, Pelotas. Anais... Pelotas: Embrapa Clima Temperado, 2007. p. 504-506.

LOPES, S.I.C. Eficiência da adubação potássica para o arroz irrigado em relação a dose, modo de incorporação e época de aplicação do adubo. In: REUNIÃO DA CULTURA DO ARROZ IRRIGADO, 19., 1991, Balneário Camboriú. Anais... Florianópolis: EMPASC, 1991. p.153-155.

LOPES, S.I.G.et al. Níveis e épocas de aplicação de potássio na cultura de arroz irrigado. In: REUNIÃO DA CULTURA DO ARROZ IRRIGADO, 21., 1995, Porto Alegre. Anais...Porto Alegre: IRGA, 1995. p.187-189.

LUANGMALAWAT, P.et al. Effect of temperature on drying characteristics and quality of cooked rice. Food Science and Thecnology: LWT, Zurich, v.41, n.4, p.716-723, 2008.

MACHADO, M.D.; FRANCO, J.C.B. Parcelamento da adubação potássica em arroz pré-germinado, no solo Pelotas (Planossolo). In: REUNIÃO DA CULTURA DO ARROZ IRRIGADO, 21., 1995, Porto Alegre.

Anais... Porto Alegre: IRGA, 1995. p.177-183.

MARCHEZAN, E.; CAMARGO, E.R.; SEGABINAZZI, T. Manejo dos fertilizantes fosfatados e potássicos em arroz irrigado no sistema pré-germinado. Bragantia, Campinas, v.66, n.2, p.219-226, 2007.

MARSCHNER, H. Mineral nutrition of higher plants. London: Academic Press, 1995. 889 p.

MENGEL, K.; KIRKBY, E.A. Principles of plant nutrition. London: Kluwer Academic, 2001. 849 p.

NTANOS, D.A.; KOUTROUBAS, S.D. Dry matter and N accumulation and translocation for Indica and Japonica rice under Mediterranean conditions. Field Crops Research, v.74, p.93-101, 2002.

SANTOS, A.B.; RABELO, R.R. Introdução e importância econômica . In: EMBRAPA ARROZ E FEIJÃO. Cultivo do Arroz Irrigado no Estado do Tocantins. Versão eletrônica, 2004. Disponível em: <http://sistemasdeproducao.cnptia.embrapa.br/FontesHTML/Arroz/ArrozIrrigadoTocantins/index.htm>. Acesso em: 21 jan. 2012.

SCIVITTARO, W.B.; GOMES, A.S. Adubação e calagem para o arroz irrigado no Rio Grande do Sul. Pelotas: Embrapa Clima Temperado, 2007. 8p. (Circular Técnica, 62) 
SEMENTES SIMÃO. Cultivares de arroz. Disponível em:

<http://www.sementessimao.com.br/site/index.php?secao=produto\#conteudo〉. Acesso em: 10 jan. 2012.

YADAV, B. K.; JINDAL, V. K. Changes in head rice yield and whiteness during milling of rough rice (Oryza sativa L.). Journal of Food Engineering, Essex, v.86, n.1, p.113-121, 2008.

ZARATIN, C.et al. Efeitos de quatro doses de potássio em seis cultivares de arroz de sequeiro irrigados por aspersão. I. Componentes de produção e produtividade. Científica, Jaboticabal, v.32, n.2, p.115-120, 2004. 
